\title{
Controversy
}

\section{Ribavirin in respiratory syncytial virus infection A double blind placebo controlled trial is needed}

At a recent workshop on infection the indications for ribavirin were discussed. Ribavirin has recently been licensed for hospital use in the United Kingdom having previously been available only on a named patient basis. Nebulised ribavirin is being vigorously promoted by the United Kingdom marketing company, Brittania Pharmaceuticals, for selected use in respiratory syncytial virus infections largely based on the 1986 guidelines of the American Academy of Pediatrics (AAP). ${ }^{1}$ The AAP suggest that nebulised ribavirin should be considered for the following patients with proved infection by respiratory syncytial virus.

(1) Patients at high risk: infants with congenital heart disease, bronchopulmonary dysplasia and other chronic lung conditions, certain premature infants, children with immune deficiency (especially severe combined immune deficiency), recent transplant recipients, and those on chemotherapy for malignancy;

(2) Severely ill infants: those with $\mathrm{PaO}_{2}$ concentrations of $<8.66 \mathrm{kPa}$ or rising $\mathrm{PaCO}_{2}$ concentrations;

(3) Infants with mild disease which may progress: infants under 6 weeks of age and those with an underlying condition such as multiple congenital anomalies, neurological or metabolic diseases.

Although one of us has previously reached similar conclusions to the $\mathrm{AAP}^{2}$ we are concerned that the climate of opinion, certainly in the United States, is tending to imply that the case for ribavirin is proved and clinical trials are no longer ethical.

There is evidence that infants with congenital heart disease ${ }^{3}$ and children with compromised immunity ${ }^{4}$ have an increased mortality from respiratory syncytial virus infection. The severity of the infection in preterm infants and the degree to which the lower respiratory tract is affected seems to increase with postnatal age..$^{5-7}$ In one study four of 23 neonates who contracted respiratory syncytial virus died, two of them suddenly and unexpectedly, although the role of the virus was unclear. ${ }^{6}$

The mortality of full term infants without underlying disease who are hospitalised with respiratory syncytial virus infection is less than $1 \% .^{\circ}$ Controlled trials of the use of ribavirin in such infants show modest improvement in clinical parameters and oxygenation, ${ }^{8-11}$ which although statistically significant is of doubtful clinical significance. Nasal shedding of respiratory syncytial virus was reduced in only one of the four studies and may anyway no reflect bronchiolar titres of the virus. ${ }^{8}$ The total number of treated infants in the four controlled trials is 62. No children in treatment or control groups died and there was no reduction in hospital stay in the only study which recorded this. ${ }^{11}$

MacDonald et al reported a mortality of $37 \%$ in infants with;congenital heart disease and infection with respiratory syncytial virus, ${ }^{3}$ but Hall et al, in a prospective trial, reported that none of seven infants with congenital heart disease or bronchopulmonary dysplasia, or both, who received placebo and none of six who received ribavirin died. ${ }^{12}$ It is possible that earlier recognition and improved conventional supportive treatment of respiratory syncytial virus infection in infants with cardiopulmonary disease may be more important than any antiviral treatment.

There are anecdotal reports of nebulised ribavirin clearing persistent respiratory syncytial virus and parainfluenza virus infections in immune deficient children who could subsequently receive bone marrow transplants. ${ }^{13} 14$ Such children are few in number and a controlled trial would be impractical. Most would agree that infection by respiratory syncytial virus in a child with severe immune deficiency is an indication for ribavirin treatment, but there is no evidence that children on chemotherapy for malignancy are helped by ribavirin.

To our knowledge there is no firm evidence that ribavirin reduces mortality, even in 'high-risk' groups, nor that it obviates the need for artificial ventilation or reduces duration of hospital stay.

Ribavirin may prevent long term morbidity, but the results of trials are awaited. There is insufficient experience on which to base assertions of its safety particularly with regard to long term toxicity. The 
cost in the United Kingdom is just over $£ 500$ for the recommended three-day course.

In our opinion the only way to resolve our doubts is a multicentre, double blind, placebo controlled trial of nebulised ribavirin for infants with preexisting cardiopulmonary disease and babies under 6 weeks old who develop proved respiratory syncytial virus infection. The main hypotheses to be tested are that nebulised ribavirin reduces the need for artificial ventilation, shortens hospital stay, and reduces mortality in one or both of these two groups. Pending the results of such a trial we would respectfully urge paediatricians to be circumspect in the use of an expensive drug that we do not feel has been proved to be of undoubted benefit. Our efforts in the interim would be better directed towards prevention of nosocomial respiratory syncytial virus infection, particularly of high risk patients, by improved handwashing and other infection control measures, and towards early identification and supportive treatment.

\section{References}

1 American Academy of Pediatrics. Policy statement: ribavirin therapy of respiratory syncytial virus. Illinois: AAP News. December 1986.

2 Isaacs D. Ribavirin. Pediatrics 1987;79:289-91.

${ }^{3}$ MacDonald NE, Hall CB, Suffin SC, Alexson C, Harris PJ, Manning JA. Respiratory syncytial virus infection in infants with congenital heart disease. $N$ Engl J Med 1982;307:397-400.

${ }^{4}$ Hall CB, Power KR, MacDonald NE, et al. Respiratory syncytial viral infection in children with compromised immune function. $N$ Engl J Med 1986;315:77-81.

5 Neligan GA, Steiner H, Gardner PS, et al. Respiratory syncytial virus infection of the newborn. $\mathrm{Br}$ Med $J$ 1970;iii:146-7.

${ }^{6}$ Hall CB, Kopelman AE, Douglas RG Jr, et al. Neonatal respiratory syncytial virus infection. $N$ Engl J Med 1979;300: 393-6.

${ }^{7}$ Mintz L, Ballard RA, Smiderman SH, Roth RS, Drew WL. Nosocomial respiratory syncytial virus infections in an intensive care nursery: rapid diagnosis by direct immunofluorescence. Pediatrics 1979;64:149-53.

${ }^{8}$ Hall CB, McBride JT, Walsh EE, et al. Aerosolized ribavirin treatment of infants with respiratory syncytial infection. A randomized double-blind study. $N$ Engl J Med 1983;308:1443-7.

9 Taber LH, Knight V, Gilbert BE, et al. Ribavirin aerosol treatment of bronchiolitis associated with respiratory syncytial virus infection in infants. Pediatrics 1983;72:613-8.

${ }^{10}$ Barry W, Cockburn F, Cornall R, Price JF, Sutherland G, Vardag A. Ribavirin aerosol for acute bronchiolitis. Arch Dis Child 1986;61:593-7.

11 Rodriguez WJ, Kim HW, Brandt CD, et al. Aerosolized ribavirin in the treatment of patients with respiratory syncytial virus disease. Pediatr Infect Dis J 1987;6:159-63.

12 Hall CB, McBride JT, Gala CL, Hildreth SW, Schnabel KC. Ribavirin treatment of respiratory syncytial viral infection in infants with underlying cardiopulmonary disease. JAMA 1985; 254:3047-51.

${ }^{13}$ Gelfand EW, McCurdy D, Pandu Rao C, Middleton PJ. Ribavirin treatment of viral pneumonitis in severe combined immunodeficiency disease [letter]. Lancet 1983;ii:732-3.

14 McIntosh K, Kurachek SC, Cairus LM, Burns JC, Goodspeed B. Treatment of respiratory viral infection in an immunodefi- cient infant with ribavirin aerosol. Am J Dis Child 1984;138: 305-8.

D Isaacs, E R Moxon, D Harvey, I Kovar, C R Madeley, R J Richardson, M Levin, A Whitelaw, and N Modi Correspondence to $\mathrm{Dr} D$ Isaacs, Department of Paediatrics, John Radcliffe Hospital, Headington, Oxford OX3 9DU.

\section{Reply from Dr Snell:}

I am grateful for the opportunity to respond to the thoughtful article from Dr Isaacs and his coauthors regarding the use of nebulised ribavirin in respiratory syncytial virus infection. In essence, they express doubts regarding the value of ribavirin and feel that a further large scale clinical trial should be carried out, in infants with pre-existing cardiopulmonary disease and neonates ('high risk infants'), in order to convince them of the efficacy of ribavirin in this situation.

The authors review only four published studies, including 62 treated infants, implying that no other data are available. This is not the case, as published data are available which document at least 175 infants treated with ribavirin, 128 in double blind, controlled clinical trials, and all these papers were made available to Dr Isaacs. In addition, further studies have been carried out which are not yet published.

The United States and the United Kingdom licensing authorities, who had access to all the existing data, published and unpublished, have granted product licenses for nebulised ribavirin in the treatment of infants and children with severe infection by respiratory syncytial virus. In so doing they have accepted the efficacy of the drug (in comparison with placebo) and its safety (as judged on a risk/benefit basis). The trials completed to date have shown statistically significant improvements in comparison with controls, in severity of illness, ${ }^{1-4}$ signs and symptoms, ${ }^{1}$ 5-7 resolution rate, ${ }^{3} 7$ oxygen saturation, ${ }^{1-3}$ need for supplemental oxygen, ${ }^{8}$ days requiring assisted ventilation, ${ }^{8}$ need for therapeutic interventions, ${ }^{7}$ duration of viral shedding, ${ }^{29}$ and IgE response to infection. ${ }^{10}$ No serious toxicity was ascribed to ribavirin in any of the published reports, controlled ${ }^{1-10}$ or open, ${ }^{1-14}$ and none has been reported to the United States Food and Drug Administration, although some 30000 infants have now received nebulised ribavirin treatment.

To clarify one specific point that has been raised; 